\title{
Editorial
}

\section{Biochemia Medica appoints the new Editor-in-Chief}

Ana-Maria Simundic

Biochemia Medica, Zagreb, Croatia

Corresponding author: am.simundic@gmail.com

Key words: editor; journal; editorial policy; scientific writing; publication

It is my great honor and pleasure to be appointed as the Editor-in-Chief of the journal Biochemia Medica. I thank the Journal Editorial Board and Executive Board of the Croatian Society of Medical Biochemists for giving me such a wonderful opportunity. I also wish to express my special thanks to prof. Elizabeta Topic and prof. Dubravka Cvoriscec. Throughout the last six years during their distinguished service as Editors-in-Chief of Biochemia Medica, this Journal has made an unprecedented progress. Their vision, commitment and professionalism have led the editorial team of this Journal on its way, continuously striving to increase its quality.

Being an Editor of a scientific journal is highly responsible and demanding role (1). Thank you both for what you have done for this Journal, for having knowledge and courage to manage the change of the journal content, editorial policy, content and design, for implementing technological improvements (2), for involving younger colleagues and giving them a chance to learn from you and work in

\section{References}

1. Marusic A. Editors as gatekeepers of responsible science. Biochem Med 2010;20:282-7.

2. Simundic AM, Topic E, Cvoriscec D. Biochemia Medica launches a new web page and an online manuscript submission system. Biochem Med 2010;20:125. such a stimulating atmosphere. The net result of your tremendous efforts is recognized by scientists and colleagues not only in Croatia, but also internationally.

We are receiving more and more submissions over time. The quality of submissions and papers published is increasing as well as the number of web site visits, citations and downloads. Last year the Journal has even got its first impact factor (3).

Maintaining this trend in such a competitive environment will therefore be my biggest challenge. I hope I will be able to manage and catalyze further improvements in the quality of this Journal, by producing the highest-quality publications, promoting the journal and making its way into some of the most prestigious bibliographic databases.

This advancement would not have been possible without the shared commitment and collaborative efforts of many individuals: editorial board members, reviewers, authors and readers. I warmly invite you all to continue supporting our work in the following years.

3. Simundic AM, Miler M, Nikolac N, Cvoriscec D, Topic E. Biochemia Medica celebrates its first impact factor. Biochem Med 2010;20:277. 